\title{
MICHEL FOUCAULT: EL GIRO GRIEGO. UNA GENEALOGÍA DEL SUJETO DEL DESEO ${ }^{1}$
}

\author{
María Cecilia Colombani` \\ Universidad de Morón/ Universidad Nacional de Mar del Plata \\ RESUMO: O presente trabalho mostra como Foucault transita pela \\ cultura grega destacando a preocupação pelo uso dos prazeres nos \\ distintos tópoi que tocam; não se trata de uma preocupação etnológica, \\ mas de uma preocupação estético-política do tópico. A vida mesma \\ se constitui em obra de arte a partir da tarefa subjetivante de tornar- \\ se um homem autônomo e é esta poíesis subjetivante que determina a \\ consolidação de um modelo étnico-antropológico a tocar a totalidade \\ dobíos.
}

PALAVRAS-CHAVE: prazeres; desejos; política; ética; estética.

\section{Una genealogía del sujeto del deseo}

Co

1 giro griego constituye una indagación sobre lo que él mismo denomina "una genealogía del sujeto del deseo" para ver en el corazón mismo de la ascesis subjetivante nuevas formas de inventarse como sujeto, por fuera de la coacción de un poder que se juega en el tópos institucional.

La Historia de la Sexualidad constituye un intento de pensar la categoría de sexualidad, un concepto tardío en la historia de Occidente, situado en el seno del siglo XIX, que Foucault intenta repensar, no como

\footnotetext{
^mcolombani@unimoron.edu.ar

${ }^{1}$ El presente trabajo, corregido, seleccionado, ampliado y adaptado a las exigencias del tema abordado forma parte de mi libro Foucault y lo Político. Buenos Aires: Prometeo, 2009.
} 
una invariable histórica, sino desde una perspectiva inscrita en una genealogía del sujeto del deseo.

El proyecto consistía pues en recorrer la historia de Occidente para ver cómo las sociedades occidentales, como configuraciones epocales, habían ido conformando una determinada experiencia.

Ahora bien, en la canónica división en períodos intelectuales que la crítica hace de la obra foucaultiana, la arqueología, la genealogía y la ética, esta preocupación domina el período ético y conviene que, en efecto, aludamos a qué nos referimos con ello. Lo que Foucault pretende es analizar una cierta dimensión estética en la configuración del modelo de subjetividad. Se trata de:

Analizar las prácticas por las que los individuos se vieron llevados a prestarse atención a ellos mismos, a descubrirse, a reconocerse y a declararse como sujetos de deseo, haciendo jugar entre unos y otros una determinada relación que les permita descubrir en el deseo la verdad de su ser, sea natural o caído. ${ }^{2}$

Esta conformación subjetiva implica formas y modalidades de la relación con uno mismo, lo que pone en el epicentro de la mirada el universo del sujeto no en relación a otro, sino en diálogo consigo mismo, terminando precisamente donde va a culminar la obra foucaultiana, en el análisis de una verdadera cultura de sí, de una epiméleia heautoû, que parece dominar el mundo romano de los dos primeros siglos del imperio.

El segundo tomo de esta Historia de la Sexualidad, "El uso de los placeres", se articula, a su vez, en cuatro grandes segmentos que constituyen cuatro tópoi de preocupación en esta tarea de constitución de la subjetividad, porque dan cuenta de cuatro enclaves donde se mide la racionalidad del sujeto, elemento indispensable en su constitución como tal: la dietética, la económica, la erótica y el verdadero amor.

En la Dietética, Foucault analiza las relaciones de los sujetos con sus propios cuerpos, relaciones inscritas en la economía general de lo que constituye la dieta para los griegos. De allí que el segmento roce cuestiones de orden médico, sellando el maridaje entre filosofía y medicina, antropología y medicina, subjetividad y medicina. Las referencias al Corpus Hipocraticum dan cuenta de esta alianza, al tiempo que muestran la red de vinculación con los distintos tópoi que bordan políticamente la constitución del sujeto.

${ }^{2}$ Cf. Foucault, M. Historia de la sexualidad. El uso de los placeres. México: Siglo XXI, 1993,p. 9. 
La Económica da cuenta de las relaciones del sujeto con un ámbito peculiar en los escenarios de subjetivación: el ôkkos, el hogar. En efecto, la casa representa un microcosmos donde se diagraman juegos de poder y dominación transidos por la racionalidad que debe acompañar al dueño de casa; espacio de lidia por el ejercicio del poder que prepara, en un isomorfismo estructural, el ejercicio del poder en la pólis. El oîkos constituye un espacio político por excelencia y en tal medida, un escenario privilegiado en la constitución de sí, que es también un enclave político. El gran interlocutor de Foucault es Jenofonte, y su radiografía del varón prudente, Iscómaco, capaz de la mejor administración del oîkos.

En tercer lugar encontramos el apartado de la erótica. Allí se problematiza el "amor a los muchachos" como un enclave de preocupación intensa, ya que el ámbito de los varones libres, portadores de derechos, constituye un tópos de fuerte problematización en el marco de la cultura clásica, de neto sesgo viril. Es el punto donde Foucault interroga dos categorías propias del mundo occidental para ver cómo resuenan en el mundo griego. Las nociones son el propio término "sexualidad" y "tolerancia". A partir de allí la propuesta foucaultiana es una verdadera genealogía de los conceptos para derribar una lectura acrítica de los mismos cuando se trata de ubicarlos en el terreno espinoso del amor a los muchachos.

El cuarto segmento, el verdadero amor, es un diálogo fecundo entre el Foucault que persigue la relación del sujeto con la verdad en la tarea de constitución de sí y el Platón del Banquete, que parece ser el escenario-texto privilegiado que da cuenta de ese maridaje entre sujeto y verdad, a la hora de pensar en los modos de subjetivación en Occidente. En los cuatro territorios, una misma preocupación se impone como nudo problemático: cuál es la relación del sujeto consigo mismo, cómo modela el hombre su conducta a propósito de la vida del cuerpo, de la institución del matrimonio, de las relaciones entre hombres y del apego a la verdad.

Sin duda, el intento de Foucault por retornar al sujeto del deseo, en una verdadera "hermenéutica del sujeto del deseo", tal como lo define en la Historia de la Sexualidad es recuperar una dimensión autónoma del sujeto; el eje de problematización que encuentra para dar cuenta de ello es el uso de los placeres, chrêsis tòn aphrodísion, como noción dominante. Foucault encuentra en la relación que los griegos y los romanos han tenido con los placeres el punto de partida de su reflexión. Los placeres parecen haber presentado un tipo de preocupación, muy distinta de la cristiana, que los hace el centro de toda una reflexión y problematización tanto de filósofos como de médicos, políticos etc. 


\section{La preocupación por las aphrodísia: la sustancia ética}

Los griegos disponían de un vasto vocabulario para connotar gestos o actos a los que comúnmente denominamos sexuales. Dice Foucault:

Disponían de un vocabulario para designar prácticas precisas; tenían términos más vagos que se referían de manera general a lo que llamamos "relación", "vínculo" o "unión" sexual: así synousía, homilía, plesiasmós, mîxis, ocheía. Pero la categoría de conjunto bajo la cual estos gestos, actos y prácticas se subsumían es mucho más difícil de captar. Los griegos utilizaban con toda naturalidad un adjetivo sustantivado: tà aphrodísia $[\ldots]$ "Cosas o placeres del amor", "relaciones sexuales", "actos de la carne", "voluptuosidades", serían algunos términos equivalentes que podríamos dar. ${ }^{3}$

Este es exactamente el campo de batalla, no la elección del partenaire. Esta preocupación por las aphrodísia es la que nos enfrenta con el concepto de "artes de la existencia", ya que "[p]or ellas hay que entender las prácticas sensatas y voluntarias por las que los hombres no sólo se fijan reglas de conducta, sino que buscan transformarse a sí mismos, modificarse en su ser singular y hacer de su vida una obra que presenta ciertos valores estéticos y responde a ciertos criterios de estilo". Verdaderas tecnologías de sí que van dibujando una prâxis continuada y sostenida para dar a la vida una forma bella. Hablar pues de las artes de la existencia es hablar de una cierta empresa transida por un télos, un fin; alcanzar la areté, la excelencia, como forma de consumación del ideal más alto. Buscar la excelencia es tarea de los áristoi, los mejores, así como es su tarea "interrogarse sobre su propia conducta, velar por ella, formarla y darse forma a sí mismos como sujetos éticos". 5

La problematización moral en torno al uso de los placeres, chrêsis tòn aphrodísion, es un viejo tema de inquietud que tuvo un escenario privilegiado en la Atenas Clásica. Las llamadas "tecnología del yo" o "artes de la existencia", tékhnai tô̂ bíou, eran, precisamente, ese cuidadoso trabajo del hombre sobre sí mismo, buscando hacer de su vida una obra de arte, al tiempo que un ejercicio de la autoridad sobre sí mismo.

${ }^{3}$ Cf. Foucault, op. cit., 1993, p. 35.

${ }^{4}$ Cf. Foucault, op. cit., 1993, p. 14-15.

${ }^{5}$ Cf. Foucault, op. cit., 1993, p. 15. 
La preocupación por las aphrodísia como sustancia ética se remonta a Platón cuando, refiriéndose al hombre tiránico, se pregunta por los diferentes tipos de deseos y afirma:

Considera, pues, lo que yo quiero señalar en los deseos. Entre los placeres y deseos no necesarios me parece que algunos son ilegítimos y tal vez sean innatos en todo hombre, pero reprimirlos por las leyes y por otros deseos mejores, y guiados y dirigidos por la razón, se desvanecen o debilitan en algunos hombres, mientras que en otros subsisten más numerosos y fuertes. ${ }^{6}$

Michel Foucault, lector de los griegos, penetra en el corazón mismo de esa problematización y sostiene que la tarea consiste en "buscar cuáles son las formas y las modalidades de la relación consigo mismo por las que el individuo se constituye y se reconoce como sujeto". ${ }^{7}$ Foucault redobla la apuesta hasta que aparezca la idea de hombres de deseo. Dice entonces: "parecía imponerse otro trabajo: estudiar los juegos de verdad en la relación de sí consigo y la constitución de sí mismo como sujeto, al tomar como dominio de referencia y campo de investigación lo que podríamos llamar 'la historia del hombre de deseo"".

Así presenta Michel Foucault su proyecto de trabajo vinculado a una historia de la sexualidad, entendida ésta como experiencia, esto es, la correlación, dentro de una cultura, entre campos de saber, tipos de normatividad y formas de subjetividad.

El proyecto lo llevó a transitar la cultura clásica y a abordar la problemática del uso de los placeres entre griegos y romanos. En efecto, parece darse cierta continuidad temática entre un contexto y otro. Hablar de una continuidad en el objeto de estudio, supone aludir a una problematización en torno a una cierta práctica, a una determinada áskesis. También en este andarivel hallamos una línea de continuidad. Este marco de análisis nos devuelve una solidaridad incuestionable: la de la reflexión y la prâxis.

Toda áskesis evoca una dimensión de máthema. Griegos y romanos conocieron esa alianza y es en base a ella que podemos comprender que toda forma de subjetividad, todo modo de constituirse como sujeto, implica un tópos de saber y un tópos de normatividad que regula la acción.

\footnotetext{
${ }^{6}$ Platón, República IX, 571 b.

${ }^{7}$ Cf. Foucault, op. cit., 1993, p. 10.

${ }^{8}$ Cf. Foucault, op. cit., 1993, p. 10
} 
Áskesis y máthesis son las bases de un dominio sobre sí, de una potestad sobre uno mismo, que implica la plena autoridad sobre el campo de la subjetividad. Quizás éste sea el hilo conductor que atraviesa toda la problematización moral de la Antigüedad; aquello que, sin dudas, constituyera una verdadera voluntad de verdad: cómo devenir un sujeto amo de sí, un verdadero conductor de una vida vivida como una obra de arte.

Dentro de esta problematización ética,

El acento se coloca sobre la relación consigo mismo que permite no dejarse llevar por los apetitos y los placeres, conservar respecto de ellos dominio y superioridad, mantener los sentidos en un estado de tranquilidad, permanecer libre de toda esclavitud interior respecto de las pasiones y alcanzar un modo de ser que puede definirse por el pleno disfrute de sí mismo o la perfecta soberanía de sí sobre sí mismo. ${ }^{9}$

\section{La Dietética: la cuestión del régimen}

El modo de preocupación que despliega Michel Foucault lo lleva a comenzar por poner el acento problemático sobre el cuerpo como primera geografía de preocupación. Es como si iniciara el recorrido por una mínima unidad para luego tender puentes hacia el afuera, la casa, la esposa, los sirvientes, los muchachos, la pólis en su conjunto. La dietética da cuenta de esa inquietud primera. En torno a ella,

La preocupación principal de esta reflexión era definir el uso de los placeres - sus condiciones favorables, su práctica útil, su disminución necesaria - en función de una determinada manera de ocuparse del propio cuerpo. La preocupación era mucho más "dietética" que "terapéutica": asunto de régimen que buscaba reglamentar una actividad reconocida como importante para la salud. ${ }^{10}$

La palabra griega díaita abre precisamente el horizonte de sentido en que se inscribe la problemática. No sólo significa un régimen, sino que nos remite a un concepto más amplio e integrador: modo de vivir, género de vida, método de vida, régimen prescrito, especialmente de alimentación, dieta, vivienda, residencia, con lo cual vemos la integración

${ }^{9}$ Cf. Foucault, op. cit., 1993, p. 31.

${ }^{10}$ Cf. Foucault, op. cit., 1993, p. 92. 
de un cierto número de elementos que guardan conexión entre sí. Si atendemos al verbo diaitáo, el horizonte de sentido refuerza el núcleo de problematización que perseguimos. El mismo alude a la noción de conservar la vida, cuidar la salud.

Ahora bien, ¿qué interés reviste la dietética en el marco de la reflexión griega y qué vinculaciones guarda con el tema de inquietud de las tékhnai tổ bíou, las artes de la existencia? Es precisamente la dieta, el régimen, una categoría privilegiada a partir de la cual puede pensarse la conducta humana; caracteriza el modo en que se administra la existencia y apunta a reglamentar un conjunto de pautas para la conducta.

¿Qué relación hay entre prácticas sociales y modos de subjetivación? En este caso, es la relación con la dieta, y por ende, con el propio cuerpo, el tópos a partir del cual se construye un determinado sujeto, surgido históricamente a partir de las prácticas que él mismo elige y se impone. La relación de este sujeto con su propio cuerpo es la bisagra; de allí que su manejo conlleva una dimensión ética, ya que roza la noción de armonía. El ajuste, el acuerdo transita por un andarivel sugerente: la armonía cuerpo-alma y sus resonancias en el concepto de salud.

Esta perspectiva abre dos campos semánticos: el dominio médico y el dominio moral. Este doble registro, el de la buena salud y el del buen mantenimiento del alma, nos hace pensar en el más remoto maridaje entre filosofía y medicina y moral y medicina. La resolución del régimen adecuado, su acabado cumplimiento y la ardua tarea del cuidado de uno mismo implican de por sí fuerza y energía moral. El tema de la buena salud no sólo tiene consecuencias en el terreno del cuerpo, como mera contrapartida de la noción de enfermedad; por el contrario, la buena salud habla de la excelencia del alma y de su sabiduría.

Así, sofía y areté, sabiduría y excelencia, pasan a ser entonces los dos fines hacia los cuales se orienta una conducta mesurada. La empresa subjetivante es sin duda una gesta teleológica, encaminada hacia un fin.

En este marco general de reflexión moral se nos impone ver los alcances entre el concepto de austeridad y la noción de mesura, sophrosýne, porque será precisamente ese concepto el que nos permita anudar el maridaje entre la reflexión sexual y la preocupación política.

Es esta vida temperante, transida por la racionalidad del hombre que conoce el riesgo de la hýbris, el esquema de comportamiento que se espera del strategós, aquel conductor que, por saber conducir su vida conforme a la excelencia de la mesura, será el mejor guardián de la pólis: aquel que sabe liberarla de la desmesura, conjurar los peligros que sobre ella se yerguen, evitar los desórdenes que pueden conducirla a un estado de a-nomía. Puede hacerlo porque antes ha sabido liberarse de sus propias 
fuerzas irracionales, conjurar los peligros que sobre él se asomaron y evitar los desórdenes que pudieron llevarlo a ser esclavo de sí mismo.

\section{La Económica: una lectura antropológica desde la perspectiva del poder}

¿Por qué motivo, en la reflexión moral que la gestión de las aphrodísia supone, hay una preocupación por la conducta sexual de los hombres casados? Se pregunta Foucault:

¿Cómo, en qué forma y a partir de qué "representaron un problema", en el pensamiento griego, las relaciones sexuales entre marido y mujer? ¿Qué razón había para preocuparse? ¿Y, sobre todo, para cuestionar el comportamiento del marido, reflexionar sobre su necesaria templanza y hacer de ello, en esa sociedad profundamente marcada por el dominio de los "hombres libres", un tema de preocupación moral?. ${ }^{11}$

La pregunta de Foucault lo pone en diálogo con Jenofonte, al tiempo que permite una lectura política del Oikonomicós de Jenofonte, en el marco de lo que constituye la positividad del poder en términos foucaultianos. Las consideraciones de Michel Foucault en torno a la problemática del poder y de su ejercicio muestran algunos elementos que, salvando las diferencias epocales entre un marco y otro, constituyen una caja de herramientas interesante para intersectar con la obra jenofontea.

La perspectiva política a su vez se complementará con una perspectiva antropológica porque el ejercicio del poder que se despliega sobre el oîkos, como unidad a administrar, supone asimismo el trabajo de administración sobre uno mismo, epiméleia heautôu, en el marco de la kalokagathía.

El término está constituido por dos adjetivos, kalós, bello y agathós, bueno, enlazados por la cópula kaí para dar cuenta de ese êthos ejemplar del que Sócrates supo dar testimonio: una vida vivida en conformidad con lo bello y lo bueno, esto es, la más alta de las vidas.

De esta suerte, un típico texto de carácter económico-político toma ribetes ético-antropológicos a partir del doble ejercicio del poder, esto es, sobre sí y sobre los demás; poder que sólo se concibe desde un dispositivo

${ }^{11}$ Cf. Foucault, op. cit., 1993, p. 132. 
educativo, con lo cual la obra gana un nuevo andarivel: el marco didácticopedagógico.

El texto es un texto político en el mejor sentido foucaultiano. No sólo porque hay tecnología política sobre el sujeto mismo en tanto sujeto que se construye éticamente, sino que hay ejercicio sobre el otro: la mujer, los sirvientes, la pólis potencial, en la medida en que el ô̂kos aparece como un terreno preparatorio del gran proyecto político de gobernar la ciudad con rectitud.

La interlocución Foucault-Jenofonte y Foucault-Platón recoge en este punto una alianza indisoluble que se da en todo el giro griego: la relación entre lo útil y la administración o uso (chrêsis). Es este vínculo entre útil-uso, el que descubre Foucault como una capa más profunda y como parte de una dimensión política en donde el buen político debe poder brindar cosas útiles a la pólis. La problemática del uso de los placeres encuentra así en la problemática de lo útil, como cosas bellas, buenas y justas, su fundamento. De esta forma, el uso de los placeres, esa administración que se ejerce sobre uno mismo, supone imprimirle un rasgo de belleza, bondad y justicia a los mismos. Hacer un buen uso de los placeres es hacer un uso bueno, bello y justo.

Un oîkos es una estructura que debe ser enriquecida, de allí que el capítulo segundo tematice los conceptos de riqueza y pobreza y de cuáles son los medios para aumentar la fortuna.

El tema dominante, como se ve, es el de la chrêsis, administración, gestión, lo cual supone previamente y como condición de posibilidad de administraciones futuras, la propia administración como sujeto, que retorna en forma de enkráteia, una actitud del sujeto sobre sí mismo, que implica una noción de auto dominio.

Se trata de tomar contacto con un modelo que opera como dispositivo educativo. El modelo es siempre la mejor enseñanza, sobre todo por esa alianza entre vida y filosofía. Iscómaco, como Sócrates, constituye ese anclaje donde la vida toma entidad filosófica; una vida vivida conforme al ideal de la kalokagathía, y que representa una trama sostenida de momentos transidos por el mismo êthos, una urdimbre donde no hay distancia entre obrar y pensar.

En ese marco de la vida vivida como obra de arte, el tema de preocupación que pone en diá-logos a dos de los más excelentes polítai es el modelo de administración del hogar.

Ahora bien, el asunto de la administración roza dos nociones capitales. Si bien se trata de administrar un bien externo al sujeto, la casa, las nociones aludidas son de carácter subjetivo: sophrosýne y enkráteia son los dos conceptos a resolver. La enkráteia, concepto asociado al 
anterior, es la condición de la sophrosýne, ya que consiste en la forma de trabajo y de control sobre uno mismo para volverse temperante. Sólo desde este doble andarivel, que asocia administración de sí más virtud, se puede administrar lo exterior. Recalcamos la actitud del sujeto frente a sí mismo en la forma del dominio de sí. En realidad el tema de la gestión del ôk os nunca debe ser entendido en el marco de un planteo económico, tal como podemos pensar contemporáneamente el término; antes bien, se trata de un abordaje moral, como toda forma de administración, por ejemplo el campo de tà aphrodísia, "actos, gestos, contactos que buscan cierta forma de placer", ${ }^{12}$ cuya gestión entraña el mismo nudo de problematización.

\section{La Erótica: los riesgos de la libido}

La reflexión foucaultiana en torno a la política como gobierno de la pólis, esto es, la administración del bien común no puede entenderse por fuera de otro tipo de administración, que a la larga va a hilvanar el ámbito privado con el público, como dos espacios donde la preocupación por lo bueno se vuelve dominante. Dice Foucault:

El uso de los placeres en la relación con los muchachos ha sido, para el pensamiento griego, un tema de inquietud, lo cual es paradójico en una sociedad que pasa por haber "tolerado" lo que llamamos "homosexualidad". Pero quizás no sea prudente aquí utilizar estos dos términos. ${ }^{13}$

En efecto, se impone una tarea de desmalezar el terreno semántico de ambos términos. No todo está tolerado en una sociedad fuertemente viril como la griega clásica. El entorno de las prácticas sexuales no está regulado por un código explícito que binarice tajantemente lo permitido de lo prohibido, pero ello no implica la ausencia de ciertas pautas que regulan la actividad y hacen de ella un tópos sobrecargado de valoraciones.

Es más, no se trata simplemente de una atención difusa, sino de una verdadera estilística en torno a la actividad sexual, que, en realidad, no difiere de una estilística en torno al más amplio campo del uso de los placeres. Lejos, pues, de estar todo tolerado, la sociedad de hombres tiene pautas claras y precisas de aquello que atenta contra la conducta

${ }^{12}$ Cf. Foucault, op. cit., 1993 , p. 39.

${ }^{13}$ Cf. Foucault, op. cit., 1993, p. 172. 
moral en términos de placeres, porque, en efecto, la conducta sexual se inscribe en un territorio moral.

En cuanto al segundo término en cuestión, la controvertida noción de homosexualidad difiere enormemente del actual concepto de la misma, sobre todo respecto a la imagen de masculinidad que ella deja traslucir.

En primer lugar, los griegos no oponían como dos elecciones antagónicas, como dos modos de comportamiento radicalmente opuestos el amor a los muchachos y aquel que se dirigía a una mujer. Menos aún existía un corpus de consideraciones que rozara la díada normalidad-anormalidad, perversión-regularidad, sino, por el contrario, un único y mismo deseo se dirigía indistintamente hacia uno $\mathrm{u}$ otro objeto de amor: "A tal punto parecía que estas dos inclinaciones eran igualmente verosímiles una como la otra y que podían coexistir perfectamente en un mismo individuo". ${ }^{14}$

No existe en la práctica algo así como dos dimensiones del deseo o la pulsión, uno noble y normal que apetece lo mismo, y otro inmoral y perverso que se dirige a un objeto de distinto sexo. El deseo es uno solo y lo que hace que se desee legítimamente a un hombre o a una mujer radica en el apetito que la naturaleza ha dispuesto en los hombres hacia lo "bello", más allá de sus diferencias de sexo. La belleza es una sola y no depende de la diferencia de sexos.

El campo político es un territorio de problematización privilegiado, ya que en la administración de los placeres, hedonaí, se está jugando fuertemente un esquema económico donde la energía que se invierte en el placer se resta a la actividad política, epicentro de la utopía clásica, en tanto administración del asunto común. El esquema entonces parece ser un modelo de austeridad sexual, más allá de preferencias en torno al compañero. Platón constituye un claro ejemplo al respecto y el modelo de la batalla perpetua es siempre sobre el campo de las aphrodísia, tópos que representa la materia ética por excelencia. La clave de la constitución subjetiva parece ser la tensión entre una posición activa o una pasiva al interior de la relación, en la medida en que una actitud pasiva representa una posición de objeto, mientras que una activa representa una posición de sujeto. La primera implica una actitud de sumisión y subordinación, mientras que la segunda, una actitud de dominación y ejercicio de la autoridad sobre el otro. Si tenemos en cuenta que el esquema de la sexualidad impacta en el horizonte político, se comprende la importancia de la tensión aludida, ya que las figuras

${ }^{14}$ Cf. Foucault, op. cit., 1993, p. 173. 
que se dibujan en el escenario son las del conductor, activo y dominante, y la del conducido, pasivo y subordinado; al primero le corresponde mandar; al segundo, obedecer. Resulta entonces que entre la sexualidad y la política parece darse una relación isomorfa, donde una de las claves interpretativas es la tensión debilidad-fortaleza. Hay un signo de debilidad en el carácter del que asume un papel pasivo frente a la fortaleza del que se muestra activo. El tema estatutario es una bisagra nodular en la configuración subjetiva y el verdadero problema lo constituyen los mancebos, jóvenes libres que aún no han completado su formación ciudadana, pero que constituyen, por supuesto, el potencial de hombres libres, portadores de derecho.

No obstante, el blanco de observación social se da allí donde se juega una apuesta socio-política por las características y personajes que la relación entraña. Dice Foucault:

La atención y la inquietud se concentran en aquellas relaciones en las que puede adivinarse que están cargadas de múltiples apuestas: aquellas que pueden anudarse entre un hombre mayor, ya de formación acabada - y de quien se supone que desempeña la función social, moral y sexualmente activa - y el más joven, que no ha alcanzado su posición definitiva y que necesita ayuda, consejos y apoyo. ${ }^{15}$

Se trata, en última instancia, en una nueva reedición del viejo tema de la sophrosýne, tan íntimamente ligado a una cuestión de límite. Se trata de reconocer el límite que territorializa al hombre al lugar de la temperancia o de la intemperancia.

Es siempre el conocimiento del límite, en este caso, articulado en la edad justa, la que constituye una bisagra territorializante y desterritorializante.

Resulta entonces que la relación se convierte en una circunstancia privilegiada donde convergen dos nociones: agón y kairós. En efecto, en primer lugar, parece abrirse una dimensión agonística en torno a la conquista del amado, habitualmente pretendido por más de uno. Habrá que pelear por la posición, persuadirlo en las ventajas de la relación, superar a otros con intenciones análogas, recurrir al prestigio, las propias cualidades, los regalos y todo aquello que legítimamente posicione al amante en el lugar óptimo, "pero la decisión pertenece al propio muchacho: en esta partida que se juega, nunca se está seguro de ganar". ${ }^{16}$

${ }^{15}$ Cf. Foucault, op. cit., 1993, p. 179-180.

${ }^{16}$ Cf. Foucault, op. cit., 1993, p. 182. 
Parece ser que el modelo de la batalla perpetua es una constante en todos los frentes de la cultura clásica, percepción verdadera si comprendemos la dimensión moral de la cuestión. La ética es siempre una relación batalladora; por eso es una preocupación viril, donde aquel que se enseñorea sobre las conductas indebidas es el amo, el hombre dueño de sí, que puede y debe, precisamente por ello, ser amo de los demás. Tomar a alguien por la fuerza, en contra de su propia libertad, es una forma de dañarse a sí mismo porque, con ello, el individuo toma la fisonomía del tirano.

En segundo lugar, la relación parece ser el kairós, el momento oportuno, la coyuntura favorable, la ocasión propicia para hacer la mejor elección por parte del muchacho, la que habrá de reportarle la mejor reputación. Nada más dulce que entregarse voluntariamente, que encontrar la mirada del amante de buen grado y entregarse a las delicias de una relación consensuada y elegida. Momento perfecto para probarse como sujeto capaz de hacer la mejor elección, aquella que lo llene de honor, que le reporte la mejor reputación y le otorgue el mejor beneficio, a partir del contacto con el adulto.

\section{Conclusiones}

Los dos ejes que se comportan como bisagras del pasaje de un tipo de relación, amorosa, a un tipo de vínculo otro, amistoso, representan dos enclaves antropológicos por excelencia, el cuerpo y el tiempo. En efecto, el cuerpo posee las características de todo lo perecedero, corruptible, engendrado, mutable, de lo que no se comporta idénticamente, lo fugaz en su constitución heterogénea. Sin advertirlo le hemos atribuido todas las características que poseen las cosas en la narrativa platónica, fundidas en el ámbito sensible, tópos que por sí mismo no puede fundamentarse ni sostenerse, precisamente por su precariedad ontológica, en tanto transido por el ser y el no ser. El tiempo opera también como una realidad afín a las cosas y al cuerpo, a partir de su mutabilidad y su fugacidad. Allí donde hay tiempo hay movimiento $y$, por ende un pasaje del ser al no ser, una muerte en lo que era, por ejemplo en la propia juventud del cuerpo del adolescente. En el marco de esta relación amenazada doblemente por el cuerpo y el tiempo, la única posibilidad de conjurar la amenaza es convertir la relación en otra cosa, por fuera del doble condicionamiento; una conversión: 
Moralmente necesaria y socialmente útil, del lazo de amor (destinado a desaparecer) en una relación de amistad, de philía. Ésta se distingue de la relación amorosa de la que proviene y de la que es deseable que nazca; es duradera, no tiene más término que la vida misma y borra las disimetrías implícitas en la relación entre el hombre y el adolescente. $^{17}$

La amistad parece ser el enclave que desdibuja los riesgos de la antigua precariedad que el amor imponía. Es deseable que nazca del corazón del amor, pero, a diferencia de aquel, no depende de la belleza del compañero, de su vigor juvenil ni de la inconstancia de los compañeros o del envejecimiento de la pareja. La ventaja de la amistad radica en la superación de la vieja disimetría de la relación, en edad, en posición, en estilo de vida etc. La philía que convertirá a los amigos en compañeros duraderos es un estado que acerca a los miembros hacia formas más simétricas, tanto en el êthos, manera de vivir, actitud de vida, como hacia los intereses comunes.

La amistad resulta así también un kairós, ya que es la ocasión de demostrar la posibilidad de transformar un vínculo de por sí difícil y complicado, por su propia naturaleza, en una relación que puede reportar el mayor beneficio: la felicidad duradera. Se trata de una apuesta a un tipo de relación que escapa de la tiranía de las pasiones para devolver la tranquilidad que sólo puede dar un vínculo de otro tipo, no contaminado por las asperezas de lo corpóreo y reparador de las inquietudes que la precariedad de los amores masculinos reporta, al tiempo que proporciona las delicias de la permanencia de la philía. Se trata de una victoria, del triunfo de la racionalidad que atraviesa al vínculo duradero por sobre la irracionalidad que suele vapulear a los amores efímeros. Así, la amistad es más afín al alma que al cuerpo en la tradicional díada metafísica que sobrevuela el tema. Por lo tanto, es deseable que ella lidere la definitiva constitución del sujeto noble, de aquel que hace de su vida una obra conforme a lo bello. El sujeto gana así dos bienes preciados que comparte con su compañero: la felicidad y la tranquilidad del alma. Se trata de dos estados permanentes, afines a la propia amistad, que se dan luego de sofocar las agitaciones que las pasiones acarrean. Si lo pensamos en términos agonísticos, es el alma superior, racional, la que se impone por sobre el alma concupiscible, asiento de los apetitos. El estado de amistad coincide con el momento de mayor racionalidad; constituye el final de un camino que se puede leer desde la metáfora del

${ }^{17}$ Cf. Foucault, op. cit., 1993, p. 185. 
viaje. La amistad es el final de una larga travesía que ha conocido los ardores del cuerpo como primera estación. En la llegada, la descripción de Jenofonte en su Banquete ilustra magistralmente el triunfo:

¿Cómo no va a ser preciso que quienes están unidos por una amistad común se miren con felicidad mutua, conversen entre sí con afecto, experimenten entre ellos recíproca confianza, que velen el uno por el otro, se complazcan en común por sus buenas acciones, si aflijan juntos si les sobreviene algún revés, que transcurran el tiempo en continua alegría cuando disfruten de salud estando juntos y que, si alguno de los dos cae enfermo, se reúnan con mayor continuidad, y que la solicitud sea todavía mayor por los ausentes que por los presentes? ? $^{18}$

Una pólis justa y moderada depende de la justicia y la moderación de los hombres que la componen. La unión de las racionalidades está anticipando la posibilidad de una ciudad que repite en el espacio público lo que acontece en el tópos privado; conocemos el isomorfismo entre las relaciones y la ciudad. Sea en el orden de la dietética, de la económica o de la erótica, el escenario resulta siempre isomorfo del estatuto de la pólis como cuerpo orgánico.

Foucault ha transitado la cultura griega relevando la preocupación por el uso de los placeres en los distintos tópoi que los mismos rozan; no se ha tratado de una preocupación etnológica de la cuestión, sino de una preocupación estético-política del tópico. La vida misma se constituye en obra de arte a partir de la tarea subjetivante de devenir un hombre autónomo y es esta poíesis subjetivante la que determina la consolidación de un modelo antropológico y político que roza la totalidad del bíos.

Larga travesía por un territorio subjetivante donde el sujeto humano ingresó en juegos de verdad, en el marco de lo que podemos denominar una práctica del yo; juegos de verdad que ya no se relacionan con prácticas coercitivas; juegos de verdad que ya no toman la forma de la ciencia o de su discurso, la forma de las instituciones encargadas del control de los sujetos; juegos de verdad que ya no definen al sujeto como el ser que habla, que trabaja y que vive. Se trata de otra cosa. El sujeto se convierte en un campo permeable a ciertas transformaciones, que sólo pueden darse por la intervención de prácticas posibilitantes de dicho cambio. Se trata entonces del conjunto de tékhnai que no sólo fijan sujetos a ciertas prácticas, sino que también vehiculizan transformaciones, rectificaciones. No hay acceso a la verdad sin tecnologías política, por

${ }^{18}$ Jenofonte, Banquete VII, 18. 
cuanto sabemos que toda tecnología está al servicio de la duplicidad subjetiva. Hay un salirse de uno mismo para convertirse en ese otro sujeto que la verdad exige como condición de contacto y esa salida sólo se produce desde la dimensión del trabajo sobre uno mismo. Este es exactamente el concepto de espiritualidad, en tanto conjunto de búsquedas, prácticas y experiencias, a través de las cuales se opera la transformación.

\section{Referencias}

COLOMBANI, M. C. Foucault y lo político. Buenos Aires: Prometeo, 2009.

EGGERS LAN, C. El sol, la línea y la caverna. Buenos Aires: Editorial Universitaria de Buenos Aires, 1975.

FOUCAULT, M. La historia de la sexualidad. El uso de los placeres. México: Siglo XXI, 1993.

. Las redes del poder. Buenos Aires: Almagesto, 1992.

. Microfísica del poder Madrid: Ediciones La Piqueta, 1995.

JAEGER, W. Paideia. México: Fondo de Cultura Económica, 1995.

PLATÓN, República. Buenos Aires: Editorial Universitaria de Buenos Aires, 1963.

XÉNOPHON.Anabase-Économique. Banquet-Dela Chasse. République des Lacédémoniens. République des Athéniens. Traduction nouvelle avec notices et notes par Pierre Chambry. Paris: Librairie Garnier Fréres, [s.d.].

ZARAGOZA, J. Introducción en Jenofonte. Recuerdos de Sócrates. Banquete. Apología de Sócrates. Buenos Aires: Planeta Deagostini, 1995. 